\title{
Kolorektal kanserlerin senkron karaciğer metastazları: Kombine cerrahi prosedür deneyimimiz
}

\section{Synchronous liver metastases of colorectal cancers: Our experience of combined surgical procedure}

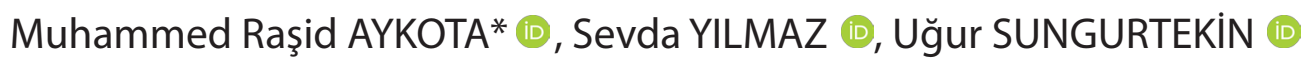

Pamukkale Üniversitesi, Tıp Fakültesi, Genel Cerrahi Anabilim Dalı, Denizli/TÜRKiYE

\section{Öz}

Amaç: Kolorektal kanserlerin (KRK) en sık metastaz yaptığı organ karaciğerdir ve tanı anında hastaların yaklaşık \%25'inde senkron karaciğer metastazı bulunur. Karaciğer metastazı olan KRK hastalarında cerrahi yaklaşım hala tartışma konusudur. Her hasta için tedavi stratejisi, hastanın performans durumuna, komorbiditelerine ve tümör aşamasına bağlı olarak kişiselleştirilmelidir. Bu çalışmanın amacı kliniğimizde senkron karaciğer metastazlı KRK hastalarına yönelik tedavi yaklaşımımızı ortaya koymak ve literatürle karşılaştırmaktır.

Gereç ve Yöntemler: Ocak 2016 ile Aralık 2018 yılları arasında senkron karaciğer metastazlı KRK tanılı, kombine cerrahi prosedür olarak adlandırılan eş seanslı kolorektal kanser ameliyatı ve hepatik rezeksiyon yapıldığı sekiz hasta çalışmaya dahil edildi.

Bulgular: İki hastaya sağ hepatektomi yapılırken, altı hastaya metastezektomi yapıldı. TNM evresine göre bir hastada (\%12) T1/2, yedi hastada (\%88) T3/4 tümör saptandı. Hastaların dördünde (\%50) lenf nodu metastazı saptandı. Bir hasta post operatif 3. günde MODS nedeniyle kaybedildi.

Sonuç: Bizim çalışmamızın sonuçlarında da olduğu gibi literatürde senkronize yaklaşım için hasta seçiminde en önemli kriterler; hasta yaşı ve yapılan hepatik rezeksiyonun hacmi olarak bildirilmiştir. Sonuç olarak cerrahi tedavi yaklaşım tercihinde, her merkez kendi protokollerini hasta özelliklerini dikkate alarak multidisipliner bir şekilde belirlemelidir.

Anahtar kelimeler: kolorektal kanser; karaciğer metastazı; cerrahi 


\begin{abstract}
Aim: The most common metastasis of colorectal cancer (CRC) is the liver and approximately $25 \%$ of patients have synchronous liver metastases at the time of diagnosis. Surgical management of CRC patients with liver metastasis is still controversial. The treatment strategy for each patient should be personalized depending on the patient's performance status, comorbidities and tumor stage. The aim of this study was to determine our treatment approach for CRC patients with synchronous liver metastasis in our clinic and to compare them with the literature.
\end{abstract}

Material and Methods: Between January 2016 and December 2018, eight patients with synchronous liver metastatic CRC, combined surgical procedure called co-operated colorectal cancer surgery and hepatic resection were included in the study.

Results: Two patients underwent right hepatectomy and six patients underwent metastasectomy. T1 / 2 tumor was detected in one patient (12\%) and T3 / 4 tumor in seven patients (88\%) according to TNM stage. Four of the patients (50\%) had lymph node metastasis. One patient died on the 3rd postoperative day due to MODS.

Conclusion: As in the results of our study, the most important criteria in patient selection for synchronous approach in literature are; The age of the patient and the volume of hepatic resection performed were reported. As a result, in the choice of surgical treatment approach, each center should determine its protocols in a multidisciplinary way considering the patient characteristics.

Keywords: colorectal cancer; liver metastasis; surgery

\section{Giriş}

Tüm dünyada her yıl 1.4 milyon yeni kolorektal kanser (KRK) tanısı konulmaktadır ve bunların 694000'i ölümle sonuçlanmaktadır [1]. Kolorektal kanserlerin en sık metastaz yaptığı organ karaciğerdir ve tanı anında hastaların yaklaşık $\% 25^{\prime} i$ senkron karaciğer metastazı bulunur. KRK hastalarının en sık ölüm sebebi karaciğer metastazlarıdır [2]. Ne yazık ki karaciğer metastazı olan KRK'lerin yaklaşık \% 20'si operasyona uygundur $[3,4]$. Bu hastaların 5 yıllık beklenen yaşam süresi cerrahi ve neoadjuvan tedaviler ile $\% 50$ arttırımış olmasına rağmen rezeksiyon yapılan karaciğer metastazı olan KRK hastalarında $\% 70$ oranında nüks görülmektedir. Bu yüzden karaciğer metastazı olan kolorektal kanser hastalarında cerrahi yaklaşım tartışma konusudur. Günümüzde pek çok tedavi yaklaşımı olsa da senkron karaciğer metastazlı KRK'de küratif tedavi potansiyeli olan girişim hepatik rezeksiyondur ve uzun dönem sağ kalımda makul bir artış sağlar [5]. Senkron karaciğer metastazlı KRK hastalarında multimodal yaklaşım tedavi alternatiflerini artırmıştır (kolorektal rezeksiyon, hepatik rezeksiyon, kemoterapi, radyoterapi). Illk girişimin primer kaynağa yönelik yapılması primer tümörün lokal tümör progresyonu (tıkanma, perforasyon, kolorektal kanama) ile ilişkili semptomların yanı sıra sonraki metastazların ana kaynağı olduğu düşünüldüğü için kullanılan geleneksel stratejidir. Geleneksel stratejilerin uzun vadeli sonuçları, ters stratejilerin (karaciğere ilk yaklaşım ve öncelikle hepatektomi yaklaşımı) önerilmesine yol açmıştır. Ters stratejilerin ardındaki fikir, kolorektal rezeksiyon yerine karaciğer rezeksiyonunu tercih etmektir (evre IV kolorektal kanserli hastaların prognozu, esas olarak karaciğer metastazlarının iyileştirilebilirliği ile belirlenir). Mevcut literatüre göre, ters stratejiler asemptomatik primer tümörü olan hastalar için uygundur. Her hasta için tedavi stratejisi, hastanın performans durumuna, komorbiditelerine ve tümör aşamasına bağlı olarak kişiselleştirilmelidir [6]. Bu çalışmanın amacı kliniğimizde senkron karaciğer metastazıı KRK hastalarına yönelik tedavi yaklaşımımızı ortaya koymak ve literatürle karşılaştırmaktır.

\section{Gereç ve Yöntemler}

Ocak 2016 ile Aralık 2018 yılları arasında senkron karaciğer metastazı KRK için kliniğimizde hepatik rezeksiyon yapılan toplam sekiz hasta çalışmaya dahil edildi. Tüm hastalara kombine cerrahi prosedür olarak adlandırılan eş seanslı kolorektal kanser ameliyatı ve hepatik rezeksiyon yapıldı. Hasta bilgileri prospektif olarak toplandı. Yaş, cinsiyet, komorbidite vb. demografik hasta bilgileri, intraoperatif parametreler ve primer tümör lokalizasyonu, tümör (TNM) evresi, lenfovasküler invazyon gibi patolojik veriler ayrıca takip süresince morbidite ve mortaliteye etki edebilecek faktörler analiz edilerek literatürdeki benzer çalışma sonuçları ile karşılaştırıldı. Verilerin istatistiksel analizi SPSS 15.0 programı kullanılarak yapıldı. Standart deviasyon, ortalama, median, frekans ve yüzdeleri hesaplandı. 


\section{Bulgular}

Çalışmaya dahil edilen hastaların üçü (\%37) erkek, beşi

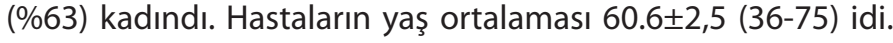
Hastaların ortalama takip süresi 14 aydı. Toplam beş hastada (\%62) hipertansiyon, diabetes mellitus vb komorbiditeler mevcuttu. Primer tümör lokalizasyonları değerlendirildiğinde; bir hastada sağ kolon, bir hastada sol kolon, üç hastada rektum, iki hastada sigmoid kolon, bir hastada ise hem sağ hem sol kolon yerleşimi saptandı. Hastaların dördünde (\%50) karaciğerde dörtten fazla metastaz mevcuttu. Major damar invazyonu hiçbir hastada yoktu. Hastaların yarısına neoadjuvan kemoradyoterapi verildi. TNM evresine göre bir hastada (\%12) T1/2, yedi hastada (\%88) T3/4 tümör saptandı. Hastaların dördünde (\%50) lenf nodu metastazı saptandı. İki hastaya sağ hepatektomi yapılırken altı hastaya metastezektomi yapıldı. Pringle manevrası, intestinal konjesyon ve tüm karaciğerde iskemiye sebep olduğundan dolayı hem intestinal anastomoz güvenliği hemde remnant karaciğer fonksiyonunu korumak için hiçbir hastaya yapılmadı. Karaciğer rezeksiyonu sonrası intraoperatif ultrason ile geride kalan karaciğer tümör odakları açısından değerlendirildi. Hiçbir hastaya peroperatif kan transfüzyonu yapılmadı. Tüm hastalara aynı seansta önce kolorektal cerrahi ekibi tarafından primer tümör rezeksiyonu sonrasında anastomoz güvenliği açısından, hepatobilier cerrahi ekip tarafından yapılan hepatik rezeksiyon sonrası aynı kolorektal cerrahi ekip tarafından anastomoz yapıldı. Hastaların ortalama yatış süresi 12 gün olarak bulundu. Hastaların yedisinde hiçbir major komplikasyon gelişmezken, bir hasta post operatif 3. günde MODS nedeniyle kaybedildi.

\section{Tartışma}

Senkron karaciğer metastazı olan kolorektal kanserli hastalarda uygun cerrahi strateji halen tartışmalıdır ve pek çok çalışmanın konusudur [7]. Senkron karaciğer metastazı bulunan KRK hastaların cerrahi tedavisinde üç ana yaklaşım mevcuttur. Bunların ilki klasik yaklaşım olarak bilinen öncelikle primer KRK'nın çıkartılması daha sonra kemoterapi uygulanması ve yaklaşık 3-6 ay sonra karaciğer metastazının çıkartılmasıdır. İkincisi ise bizim çalışmamızda da olduğu gibi kombine yaklaşım olarak bilinen karaciğer metastazının ve primer tümörün aynı seansta çıkartıldığı cerrahi prosedürdür. Üçüncü yaklaşım, ilk önce karaciğer metastazının çıkartılması, daha sonra kemoradyoterapi uygulanması ve son aşama olarak primer tümörün çıkartıldığı ters strateji olarak bilinen prosedürdür [8].

2018 yılında İngiltere'de 1830 hastanın değerlendirildiği bir çalışmada hastaların \%71,1'i klasik yaklaşım ile, \%14,8'i kombine yaklaşım ile, \%14,2'si ters strateji ile tedavi edilmiştir. Klasik yaklaşımın barsak ilişkili komplikasyonların önlenmesinde ve primer tümörün progresyonundan kaynaklı komplikasyonların önlenmesinde etkili olduğu bildirilmiştir. Ters yaklaşım stratejisi ise primer tümörün çıkartılamadığı lokal ileri KRK hastalarında, postoperatif karaciğer yetmezliğinin önlenmesinde ve kemoradyoterapiye dirençli karaciğer metastazlarının tedavisinde belirgin olarak avantajlı bulunmuştur [8]. Ayrıca literatürde iki aşamalı cerrahi yaklaşımların postoperatif komplikasyon ve tümör progresyonu açısından daha yüksek riskli olduğu bildirilmiştir $[8,9]$.

Aynı seansta hem kolorektal kanser rezeksiyonunun hem de karaciğer metastaz rezeksiyonunun yapıldığı diğer çalışmalarda da çalışmamızda olduğu gibi tedavi başarısında hasta seçiminin önemli olduğu, bu prosedür ile hastanede yatış süresinin ve maliyetin azaltıldığı ve klinik sonuçlarının diğer prosedürlere göre daha başarılı olduğu bildirilmiştir [10]. 1430 hastanın değerlendirildiği senkron ve kombine yaklaşımların karşılaştırıldığı bir çalışmada 5 yıllık beklenen sağkalım süresi oranlarında anlamlı farklılık saptanmamıştır [11]. Bizim çalışmamızın sonuçlarında da olduğu gibi literatürde senkronize yaklaşım için hasta seçiminde en önemli kriterler; hasta yaşı ve yapılan hepatik rezeksiyonun hacmi olarak bildirilmiştir $[12,13]$.

\section{Sonuç}

Cerrahi tedavi yaklaşım tercihinde, her merkez kendi protokollerini hasta bazlı özellikleri dikkate alarak multidisipliner bir şekilde belirlemelidir.

\section{Çıkar çatışması / finansal destek beyanı}

Bu yazıdaki hiçbir yazarın herhangi bir çıkar çatışması yoktur. Yazının herhangi bir finansal desteği yoktur.

\section{Kaynaklar}

1. Ferlay J, Soerjomataram I, Dikshit R, Eser S, Mathers C, Rebelo $M$ et al. Cancer incidence and mortality worldwide: sources, methods and major patterns in GLOBOCAN 2012. Int J Cancer 2015; 136: 359-86

2. McMillan DC, McArdle CS. Epidemiology of colorectal liver metastases. Surg Oncol 2007; 16: 3-5.

3. Xu F, Tang B, Jin T-Q, Dai C-L. Current status of surgical treatment of colorectal liver metastases. World J Clin Cases 2018;6: 716-34.

4. Line P-D, Hagness M, Dueland S. The Potential Role of Liver Transplantation as a Treatment Option in Colorectal Liver Metastases. Can J Gastroenterol Hepatol 2018; 2018: 8547940. 
5. Tsai M-S, Su Y-H, Ho M-C, Liang J-T, Chen T-P, Lai H-S, et al Clinicopathological features and prognosis in resectable synchronous and metachronous colorectal liver metastasis. Ann Surg Oncol 2007;14: 786-94.

6. Ihnát $\mathrm{P}$, Ostruszka $\mathrm{P}$, Vávra $\mathrm{P}$, Peteja $\mathrm{M}$, Zonča $\mathrm{P}$. Treatment strategies for patients with colorectal carcinomaand synchronous liver metastases. Rozhl V Chir Mesicnik Ceskoslovenske Chir Spolecnosti 2018;97: 451-54.

7. Thelen A, Jonas S, Benckert C, Spinelli A, Lopez-Hänninen E, Rudolph $B$, et al. Simultaneous versus staged liver resection of synchronous liver metastases from colorectal cancer. Int J Colorectal Dis 2007; 22: 1269-76.

8. Sturesson C, Valdimarsson VT, Blomstrand E, Eriksson S, Nilsson $J \mathrm{H}$, Syk I, et al. Liver-first strategy for synchronous colorectal liver metastases - an intention-to-treat analysis. HPB 2017;19: 52-8.

9. Propensity score-matched outcomes analysis of the liver-first approach for synchronous colorectal liver metastases. - PubMed - NCBI [Internet]. [cited 2019 Apr 18]. Available from: https:// www.ncbi.nlm.nih.gov/pubmed/26864820
10. Le Souder EB, Azin A, Hirpara DH, Walker R, Cleary S, Quereshy F. Considering the cost of a simultaneous versus staged approach to resection of colorectal cancer with synchronous liver metastases in a publicly funded healthcare model. J Surg Oncol $2018 ; 117: 1376-85$.

11. Silberhumer GR, Paty PB, Denton B, Guillem J, Gonen M, Araujo $\mathrm{RLC}$, et al. Long-term oncologic outcomes for simultaneous resection of synchronous metastatic liver and primary colorectal cancer. Surgery. 2016;160(1):67-73.

12. Nanji S, Mackillop WJ, Wei X, Booth CM. Simultaneous resection of primary colorectal cancer and synchronous liver metastases: a population-based study. Can J Surg J Can Chir 2017;60: 122-28.

13. Yin Z, Liu C, Chen Y, Bai Y, Shang C, Yin R et al. Timing of hepatectomy in resectable synchronous colorectal liver metastases (SCRLM): Simultaneous or delayed? Hepatol Baltim Md 2013;57: 2346-57. 